\title{
Implicações penais do linchamento virtual com foco no comportamento sexual da mulher: disseminação do discurso de ódio nas relações de gênero sob uma perspectiva criminológica feminista
}

\author{
Criminal implications of virtual lynching focusing on women's \\ sexual behavior: Disseminating hate speech in gender relations \\ from a feminist criminological perspective
}

FRANCISCO FRANÇA JÚNIOR

Centro Universitário CESMAC (Maceió/AL)

Ana Cecília de Morais e Silva Dantas

Centro Universitário CESMAC (Maceió/AL)

Roneide LuCia da SiLva

Centro Universitário CESMAC (Maceió/AL)

RESUMO Este artigo tem por objetivo principal investigar criticamente as implicações penais do linchamento virtual diante do comportamento sexual das mulheres. Pretende-se, portanto, refletir se e por que as mulheres são as vítimas preferenciais desse tipo de crime virtual e como essa dinâmica nociva tem se desenvolvido na dinâmica social moderna. Nesse sentido, diante de uma sociedade que (ainda) reprime e, muitas vezes, até subjuga mulheres pelo simples fato de serem o que são (ou seja, mulheres), constatou-se que esse tipo de prática nociva, no contexto da sexualidade feminina, ainda se faz presente, possibilitando a circularidade de uma violência com raízes historicamente situadas. Para tanto, adotou-se o método hipotético-dedutivo a partir de uma revisão bibliográfica pontual.

Palavras-chave: Linchamento virtual. Vitimização. Sexualidade. Mulheres.

ABSTRACT This article aims to critically investigate the criminal implications of virtual lynching in the face of women's sexual behaviour. It is intended, therefore, to reflect on why women are the preferred victims of this type of cybercrime and how this harmful dynamic has developed in the modern social dynamic. In this sense, in the face of a society that (still) represses and often even subjugates women simply because they are what they are (women), it was found that this type of harmful practice in the context of female sexuality, 
is still present, allowing the circularity of a violence with historically situated roots. Therefore, the hypothetical-deductive method was adopted from a punctual literature review. Keywords: Virtual Lynching. Victimization. Sexuality. Women.

\section{INTRODUÇÃo}

$\mathrm{O}$ agigantamento da tecnologia no contexto social e a liquidez ${ }^{1}$ nas relações humanas no mundo (pós)moderno fizeram que o espaço cibernético se tornasse um lugar consideravelmente hostil. Se por um lado, as redes sociais, nesse ambiente virtualizado, são como um lugar de libertação, um importante meio de democratização do conhecimento; por outro, são também um espaço de certa acidez no trato pessoal, além de disseminação do discurso de ódio. É nesse contexto que há de se constatar que, embora seja esse um fenômeno próprio da (pós)modernidade, possibilitado especialmente pela internet, não pode o mesmo ser encarado como algo propriamente novo, vez que esse tipo de ambiente de opressão, marginalização e, por vezes, de subordinação das mulheres às expectativas masculinas faz parte de uma tradição de raiz patriarcal e machista, que limita sua autonomia social, econômica e até sexual. ${ }^{2}$

É importante evidenciar desde já que a apresentação do tema proposto parte também da necessidade de aprimorar o estudo sobre os crimes virtuais, mais precisamente a respeito desse tipo de crime envolvendo as mulheres e o seu comportamento sexual. Interessa-nos saber, por exemplo, quais são exatamente as implicações penais? Além disso, por que as mulheres, da nossa perspectiva, continuam sendo as vítimas preferenciais de julgamentos sexualmente preconceituosos no espaço cibernético? Será preciso, portanto, discutirmos como a "violência virtual" se torna mais uma ferramenta de subjugação das mulheres, colocando-as como principais destinatárias do linchamento virtual, que, assim como o linchamento físico, ${ }^{3}$ tem como objetivo uma espécie de correção moral daqueles que fogem dos padrões sociais.

Dessa maneira, diante das problemáticas postas, uma das hipóteses a ser defendida é a ideia de que as mulheres são as vítimas preferenciais de crimes virtuais - e, por consequência, dos linchamentos de cunho moralizante -, sobretudo quando o assunto é o seu comportamento sexual, tendo em vista que a internet tem sido, de uma maneira geral, um lugar onde se tem permitido a continuidade de um sistema sociojurídico tradicionalmente machista e patriarcal, em que se disseminam diversas formas de violência (vinculadas ao gênero, à orientação sexual, à questões econômicas, patrimoniais, psicológicas etc.), que não raramente tem colocado a mulher como um mero objeto. Outra de nossas hipóteses

1 Expressão aqui utilizada no contexto da seguinte literatura: BAUMAN, Zigmunt. Amor líquido: sobre a fragilidade dos laços humanos. Rio de Janeiro: Jorge Zahar. Editor, 2004.

2 Para uma análise aprofundada, veja-se: CUNHA, Bárbara Madruga da. Violência contra a mulher, direito e patriarcado: perspectivas de combate à violência de gênero (artigo classificado em $7^{\circ}$. lugar na XVI Jornada de Iniciação Cientifica de Direito da UFPR 2014). Disponível em: http://www.direito.ufpr.br. Acesso em: 17 out. 2019.

3 Do qual, aliás, os homens parecem as maiores vítimas, conforme se constata em: MARTINS, José de Souza. Linchamentos: a justiça popular do Brasil. São Paulo: Contexto, 2015. 
diz respeito à (in)devida interferência estatal nessas relações envolvendo as mulheres e sua intimidade sexual no espaço cibernético.

Assim, com o fim de abordar devidamente o assunto e explorar tais hipóteses, o objetivo principal da presente investigação consiste em analisar criticamente as implicações penais do linchamento virtual diante do comportamento sexual das mulheres, além de avaliar, ainda que de maneira sucinta, como a literatura e a legislação penal tem se comportado sobre o tema. O resultado da pesquisa, portanto, divide-se basicamente em três etapas, quais sejam: a) no primeiro capítulo, embora nossa abordagem não seja propriamente histórica, procuramos retratar muito ligeiramente como surgiu a questão dos linchamentos físicos e como estes se articulam com os linchamentos virtuais; b) já no segundo capítulo, passaremos em revista as principais implicações penais desse tipo de comportamento contra as mulheres e analisaremos ainda em quais esferas elas se desdobram; c) e, por fim, no terceiro capítulo, discutiremos, da perspectiva das vítimas, os casos de linchamentos virtuais no tocante ao comportamento sexual, procurando identificar por que são as mulheres as que mais sofrem com esse tipo de prática.

Nessa ordem de ideias, nosso principal referencial teórico consistirá, como não poderia deixar de ser, especialmente em obras da criminologia feminista - onde as mulheres têm voz e vez prioritárias -, entre as quais se destacam as reflexões encontradas no artigo intitulado "E quando a vítima é mulher? Uma análise crítica do discurso das principais obras de direito penal e a violência simbólica no tratamento das mulheres vítimas de crimes contra a dignidade sexual", e em Bárbara Madruga da Cunha, com o artigo intitulado "Violência contra a mulher, direito e patriarcado: perspectivas de combate à violência de gênero". As mencionadas autoras, com uma literatura de apoio, constituída também de homens, porque não nos interessa radicalizar na segregação, vão nos permitir entender por que determinadas situações no ambiente virtual atingem em maior proporção e intensidade as mulheres e sua sexualidade.

Por fim, o método aqui utilizado será o hipotético-dedutivo, isto é, nossa preocupação será a de perspectivar os problemas propostos de uma maneira geral, propondo, a partir deles, reflexões sobre as hipóteses sustentadas. Logo, vamos procurar refletir criticamente a respeito das eventuais incoerências nessa dinâmica social discriminatória, tomando por base uma revisão bibliográfica pontual, revelando como está a situação acerca da temática abordada.

\section{ENTRE O LINCHAMENTO FÍSICO E O VIRTUAL}

Para começarmos, um melhor entendimento semântico acerca do que é exatamente o linchamento pode ser obtido no próprio dicionário, que nos diz que o ato de linchar é: "justiçar sumariamente sem qualquer espécie de julgamento legal" (AURÉLIO, 2001, p. 459). No entanto, da perspectiva sociológica, o que percebemos é que os linchamentos podem ser considerados como manifestações simbólicas contra o poder estatal em busca do ideal de "justiça", o que muitas vezes é proporcionado pelo acentuado sentimento de frustração em relação às promessas de segurança realizadas pelo ordenamento jurídico em vigência.

Desse ponto de vista, José de Souza Martins assevera que o "linchamento é um ato de punição coletiva, regido por uma concepção de castigo que já não existe nos nossos 
códigos e leis, que são expressões da Razão" (2015, p. 112). Esse tipo de castigo social nos remete a tempos primitivos de punição, em que temos a disseminação da vingança privada, onde a população é dominada por um sentimento de revolta para com aqueles que não cumprem aquilo que é preestabelecido socialmente. Na mesma linha de raciocínio, tem-se o debate sobre a ideia de autotutela, onde uma de suas principais características seria o exercício da força física.

Com isso, fica evidente que se trata de um modelo de justiça que nos remete à primitividade, à selvageria, de movimentos irracionais, em cuja intenção principal dos linchadores é a punição sumária, sem a possibilidade de qualquer defesa. Para José de Souza Martins, “o ato de linchar é uma tentativa de 'consertar' a sociedade e colocá-la no rumo da sociedade imaginada" (2015, p. 65). Segundo ele, "no geral, os linchamentos nos fazem ainda medievais, na medida em que são práticas de punição que procuram cobrir o linchado de desonra, destituindo-se de sua humanidade, até o extremo da desfiguração e da sua redução a cinzas" (2015, p. 118).

Diante de tais argumentos, constata-se que essas práticas, reconhecidas como linchamentos, possuem certa linha "moral", tentando assim impor valores e regras de conduta para os que compõem a sociedade. É um tipo de violência motivado pela emoção, pelo desejo de vingança, e que tem por característica uma durabilidade do ódio circunstancialmente produzido. Não obstante, forçoso é reconhecermos que essa dinâmica de violência não se viu contida na esfera física, transportando-se também para o ambiente virtual, onde se observam características muito próprias pela facilidade (jamais vista) de disseminação das informações.

Assim, pela fluidez típica do próprio meio, o ambiente virtual está sempre se atualizando e se modificando, estando cada vez mais presente no cotidiano das pessoas. No entanto, o que acontece no virtual tem implicações no mundo encarado como "real". Com isso, a internet se torna um instrumento capaz de causar grandes feitos, tanto positivos, como negativos. Conforme Manuel Castells: "o que a internet faz é processar a virtualidade e transformá-la em nossa realidade, constituindo a sociedade em rede, que é a sociedade em que vivemos" (2003, p. 287). Dessa forma, uma coisa é certa, o virtual veio para transformar as relações humanas.

O que atualmente definimos como tecnologia e virtual, para o autor Pierre Lévy significa ciberespaço, definido por ele "como o espaço de comunicação aberto pela interconexão mundial de computadores e de memórias dos computadores" (1999, p. 92). Em um de seus livros, Lévy reflete sobre o que seria o virtual, começando pela origem da palavra, que vem do latim medieval, que significa força, potência. Nessa perspectiva, o significado adotado pela filosofia escolástica, por exemplo, diz que "virtual é aquilo que existe em potência e não em ato, que carrega em si as problemáticas [...]" (LÉVY, 1996, p. 5).

Dessa maneira, o que se percebe é que a internet é normalmente utilizada para ocupar, com a maior rapidez possível, um espaço maior de visibilidade naquilo que se divulga, sobretudo na (des)construção da imagem das pessoas (sejam elas físicas ou jurídicas). É nessa esteira que se estabeleceram massivamente as chamadas redes sociais, como o Facebook, o Instagram e o WhatsApp. É justamente por essa força dissuasiva, e de alta capacidade de disseminação social, que, para nós, apresenta-se como imprescindível debater essa 
dinâmica de funcionamento na virtualidade, especialmente para que nos seja permitido entender os linchamentos, agora também virtuais, no contexto do comportamento sexual das mulheres.

Não se perca de vista que as redes sociais, como explica Lévy (1996, p. 15-16), seriam uma ampliação da realidade, ou seja, são uma continuidade desta, mas que nos proporcionam novas possibilidades. Elas nos permitem uma conexão com outras pessoas, que falemos com qualquer pessoa (que também esteja on-line), em qualquer lugar e hora. No que toca aos linchamentos virtuais, aqueles que participam têm, por vezes, a sensação de garantido anonimato e a certeza da irresponsabilidade, em que não há propriamente uma noção das consequências que determinadas postagens nessas redes sociais podem provocar (seja na vida da vítima, seja na daqueles que se travestem na condição de "juízes da moral"). Veja-se que, para Karen Macedo:

\footnotetext{
[...] Não se está mais sozinho, mas em rede de relacionamento, onde há partilha de todos com todos e mobilização política. Como influência dessas potencialidades nos julgamentos e justiçamentos on-line, podemos destacar o que muda: a dimensão do evento, a dimensão do alcance das mensagens a ele relacionadas e também a dimensão das punições (2016, p. 57).
}

Não raramente, postagens realizadas nas redes sociais fazem parte desse ritual de justiçamento moral, em que ocorem nesse processo a divulgação de boatos, sobretudo por meio de imagens, cujo único propósito é abalar a imagem de determinadas pessoas. O problema é que a alta propagação dessas maledicências sobre os outros gera consequências negativas variadas. De acordo com Castells, "a internet é a rede que liga a maior parte das redes" (2016, p. 430), ou seja, a internet é ferramenta no cotidiano da maioria da população, ainda no entendimento do autor, "de certo modo, toda realidade é percebida de maneira virtual" (2016, p. 455).

Sendo assim, um linchamento virtual geralmente tem a participação de milhares de pessoas distribuindo informações negativas sobre determinada pessoa. Muitas delas com sentimentos de ódio, com xingamentos e até ameaças contra uma pessoa que, de imediato, pouca coisa (ou quase nada!) pode fazer contra esse processo degradante. As pessoas que praticam esse tipo de ato, não raramente, não se sentem atacando uma pessoa de carne e osso, mas sim uma tela, uma imagem, uma mera fotografia, motivo pelo qual acabam se sentindo mais encorajadas a fazê-lo. Além disso, por ser geralmente uma ação em massa, esses linchadores, como dissemos, acham que estão em anonimato e que assim ficarão impunes, pois se veem apenas como mais um entre tantos que estão participando. Macedo nos explica que:

Esse contexto novo para a formação de discursos permitiu também que antigas
práticas sociais aflorassem e se popularizassem nas redes sociais on-line, como
preconceito, julgamento, acusação, denúncia, monitoramento sobre o compor-
tamento do "outro" e até uma vigilância contínua sobre si mesmo (2016, p. 61).

Portanto, constata-se facilmente que, com a chegada da internet e, por conseguinte, das redes sociais, antigas práticas foram se adaptando e sendo replicadas. Como já explicado, com os linchamentos as pessoas punem com a intenção de corrigir certos tipos de com- 
portamentos que fogem do que é padronizado socialmente como o correto. Da perspectiva moral, historicamente, é inegável que quem mais sofre por conta dessas padronizações, principalmente no que toca ao recato e ao pudor, são as mulheres. Para que se tenha uma ligeira ideia, apenas na década de 1970 (não faz muito!) é que se permitiu que as mulheres pudessem se divorciar. Além disso, até o advento da 11.105/2006 também não se permitia a existência de crime de posse sexual mediante fraude quando a mulher não era encarada como honesta (art. 215 do código penal).

É justamente por isso que sustentamos inicialmente a hipótese de que, nessa (pós) modernidade, são elas as que mais sofrem linchamentos virtuais no tocante ao seu comportamento sexual, haja vista que, se o mesmo tipo de comportamento ocorre com relação ao comportamento sexual de um homem, em sendo a relação heterossexual, as consequências não parecem chocar negativamente a sociedade como ocorre com as mulheres. Muito ao contrário. Nesse contexto, os homens tendem a ser vistos como aqueles que estão atendendo exatamente às expectativas sociais que sobre eles recaem, ou seja, estão exercendo a sua masculinidade.

Essa pretensão de "correção moral", em especial das mulheres, repise-se, tornou-se ainda mais intensa e gravosa por meio das redes sociais, que, com a facilidade de propagação, faz que a postagem tenha proporções inimagináveis, potencializando-se o dano em todas as esferas da vida. Entretanto, ao contrário do que muitos pensam, essas práticas podem ser enfrentadas por intermédio do âmbito penal. A publicação de ofensas e fotos de cunho íntimo tem sim consequências jurídicas. É, portanto, já sabido, que o exercício do jus puniendi pertence aos agentes públicos incumbidos da persecução penal, ou seja, é poder/dever estatal responsabilizar aqueles que contrariam, sem motivo justo, as regras legalmente prescritas, desde que, em ambiente que se pretende como democrático, através de um devido processo legal.

\section{Algumas das IMPLiCAÇÕES PENAIS DO LiNCHAMENTO VIRTUAL: O FOCO NO COMPORTAMENTO SEXUAL DAS MULHERES}

Como já deixamos antever, os linchamentos virtuais são um tipo de violência (pós) moderna que reflete em diversas áreas do convívio social. Bens jurídicos dos mais variados, mesmo os que não possuem um valor patrimonial diretamente mensurável, por exemplo, a autoestima e a própria sanidade mental podem ser relacionados nesse contexto. Não nos custa, portanto, repisar, conforme nos explica Phillipe Giovanni Silva, que "a facilidade do sigilo para efetivar práticas criminosas fez do universo digital o meio ideal para a concretização e o sucesso de práticas criminosas, entre eles, as tradicionais violências de gênero" (2018, p. 30).

Embora não exista um dispositivo que especifique textualmente o linchamento virtual, isso não significa dizer que, no Brasil, essa conduta não possua amparo jurídico-criminal. Primeiro porque, é perfeitamente possível relacionar tal comportamento aos chamados crimes contra a honra, com previsão a partir do artigo 138 do código penal. Segundo porque, ainda nesse diploma legal, mesmo que o sujeito alegue ter algum motivo para disseminar o conteúdo com potencial para macular outrem, será possível nos deslocarmos até o artigo 
345, que trata de criminalizar o "fazer justiça com as próprias mãos". E terceiro porque, tem-se, mais recentemente, o advento da lei n. 13.718/2018, que mais se aproxima do tema enfocado, uma vez que trata de matéria atinente à exposição da intimidade sexual das pessoas sem devida autorização, com a chamada pornografia de vingança, o que nos remete ao título dos crimes contra a dignidade sexual.

No que diz respeito à honra, vale salientar que a mesma é encarada como um direito penalmente protegido, onde a doutrina e a jurisprudência a têm classificado de duas maneiras: a) como objetiva, aquela que tem por características a afetação da reputação da pessoa, isto é, o conceito que as outras pessoas têm sobre nós, enfim, sobre nossas peculiaridades; e b) como subjetiva, que, por sua vez, representa o sentimento ou definição que temos sobre nós mesmos, onde está situada, por exemplo, nossa autoestima. Pelo que se extrai de Cezar Roberto Bitencourt, resumidamente, “enquanto a honra subjetiva representa o sentimento ou a concepção que temos a nosso respeito, a honra objetiva constitui o sentimento ou o conceito que os demais membros da comunidade têm sobre nós, sobre nossos atributos" (2019, p. 422).

Assim, no âmbito do Código Penal, dito melhor especificadamente, a calúnia (art. 138) é constituída a partir de uma imputação falsa a uma pessoa de determinado fato que é definido como crime. Já no caso da difamação (art. 139), temos a atribuição a alguém de um fato que é ofensivo para a sua reputação. Nesse caso, não é necessário que seja algo tipificado como crime, podendo tal se constituir, portanto, quando alguém divulga conteúdo de cunho sexual da vítima, atingindo, assim, sua honra objetiva. Por fim, com relação à injúria (art. 140), o comportamento terá o condão de abalar a honra subjetiva, isto é, como antevisto, refere-se ao sentimento e à concepção de dignidade que temos sobre nós mesmos, à própria autoestima.

Ademais, os referidos crimes contra a honra são, na generalidade, considerados de menor potencial ofensivo, pelo que, por regra, são julgados nos Juizados Especiais Criminais, conforme os artigos 60 e 61 da Lei $n^{\circ} .9 .099 / 1995$, o que permitirá prontamente, ao menos em tese (já que se for uma situação de violência no contexto doméstico estará desse âmbito excluída por força do art. 41 da Lei 11.340/2006), a utilização dos benefícios da transação penal (art. 72s.) e da suspensão condicional do processo (art. 89). Logo, considerar nesses termos os linchamentos virtuais, mormente os de cunho sexual, mostra-se, do nosso ponto de vista, desalinhado com as graves consequências que essas situações podem provocar na vida das vítimas. Algumas delas, inclusive, desenvolvem a depressão, isolam-se com vergonha, perdem o emprego, o convívio familiar, abandonam a escola, existindo ainda relatos de suicídio (VALENTE; NERIS; RUIZ E BULGARELLI, 2016, p. 2).

Contudo, o que sustentamos como uma de nossas hipóteses é a ideia de que o linchamento virtual por conta do comportamento sexual de determinadas mulheres, que têm imagens divulgadas desautorizadamente nas redes sociais, não se trata de um mero crime contra a honra, contra a imagem, qualquer que seja a natureza, mas de uma situação que pode ser denominada como de lesa-dignidade, em que, na maior parte das vezes, a motivação para a divulgação é eminentemente de cunho machista (a vingança por uma suposta traição ou a necessidade de se vangloriar da conquista), procurando desabonar a imagem da vítima como mulher (cidadã, mãe, esposa, filha etc.), enquanto pessoa sujeita de direitos 
como qualquer outra, e, portanto, merecedora de respeito independentemente de seu comportamento sexual revelado indevidamente.

Nesse passo, o que se percebe é que a exposição das imagens íntimas de uma mulher ocorre normalmente com o fito de se demonstrar, principalmente para os integrantes de seu círculo social, que ela não é uma mulher digna de respeito (o que, como já mencionamos alhures, nas mesmas circunstâncias, geralmente não ocorre com os homens, os quais são muitas vezes exaltados socialmente no círculo de amizades justamente por isso) e, assim, deixar manchada sua imagem, colocando-a numa posição de absoluta inferioridade, sobretudo em relação aos indivíduos do sexo masculino. Veja-se que Valente, Neris, Ruiz e Bulgarelli esclarecem que:

\footnotetext{
...a barganha tradicional estabelecida em torno da sexualidade da mulher e suas relações com o homem é que, se ela se comporta como esperado (de acordo com normativas de gênero, ou representações dominantes), é protegida pelo homem; se não, o homem pode violá-la e puni-la.

$[\ldots]$

Para além dos danos físicos e psicológicos causados pela ameaça, o perigo do ataque sexual passa a operar como uma lembrança do privilégio masculino, com o intuito de restringir o comportamento das mulheres (2016, p. 14).
}

Ainda no código penal, como dissemos, pode-se cogitar a utilização do exercício arbitrário das próprias razões, isto é, o fazer justiça com as próprias mãos (art. 345), em situação em que o sujeito, ao se sentir "prejudicado" por suposta conduta praticada pela vítima, resolve divulgar as imagens captadas outrora na intimidade do casal, para ver reestabelecida uma situação que se idealiza como justa. Uma justiça idealizada apenas na cabeça do sujeito, por óbvio, uma vez que, ao menos em ambiente que se pretende democrático, não se faz justiça ofendendo a tão sorrateiramente dignidade alheia. Em casos de suposta traição ou término do relacionamento, em que o sujeito não aceita a condição de "preterido por outro", é comum que, para ver restituída sua "imagem", comporte-se o agressor prejudicando a vítima, mostrando para ela que aquilo é moralmente inaceitável e que, por isso, ela deve pagar com sua reputação. Mas essa, por razões evidentes, também não é uma tipificação que julgamos como a mais adequada.

Não se perca aqui a oportunidade de destacar novamente que todas essas questões de grave violação de direitos das mulheres, de imposição de regras de recado e de pudor, existem há muito tempo, todavia o comportamento sexual de homens e mulheres se transformou com o advento da (pós)modernidade, assim como a relação social dos seres humanos de uma maneira geral se transformou. Mas, as mulheres, em especial, não estão mais sujeitas às mesmas condições que décadas atrás estavam. O mundo não se relaciona da mesma maneira, os crimes que antes implicariam em consequências e divulgações em determinada região que ocorrera hoje a depender da gravidade pode ser propagado em todo o país por meio das redes sociais de interação e isso precisa ser melhor regulamentado para que assim a segurança no mundo virtual seja realmente efetivada. Conforme Leandro Ayres: "os cybercrimes são crimes novos, que precisam de novas criminologias para uma melhor conceituação" (2017, p. 221). 
É, portanto, necessário que os legisladores criem uma adequada e precisa regulamentação, não propriamente penal, para essas condutas extremamente ofensivas à dignidade feminina. Essa exposição sorrateira do corpo feminino, com a conotação sexual em especial, é uma barreira da dignidade que preocupa. A partir daí, a opção acolhida pelo legislador brasileiro (criticável, é bem verdade, mas não entraremos nesse mérito porque foge de nossos objetivos) foi a utilização do direito penal, com a edição e a entrada em vigência das leis n. 13.718/2018 e 13.772/2018, que alteraram o código penal, acrescentando, entre outras modificações, os artigos 216-B e 218-C. O primeiro trata da captura ou registro da imagem das pessoas em momentos de intimidade sexual. Já o segundo tipifica a propagação de tais imagens de cunho íntimo sem o consentimento dos participantes. Para Bitencourt:

\begin{abstract}
Protege-se, genericamente, a dignidade sexual individual, de homem e mulher, indistintamente, consubstanciada na liberdade sexual e direito de escolha, especialmente da mulher que é, com mais frequência, exposta nas redes sociais por excompanheiros, namorados ou cônjuges, inclusive por vingança ou apenas para humilhar. Em outros termos, o presente tipo penal insere-se na finalidade abrangente de garantir a todo ser humano, que tenha capacidade de autodeterminar-se sexualmente, que o faça com liberdade de escolha e vontade consciente, mas, principalmente, preservando a sua privacidade, que é assegurada, inclusive, constitucionalmente (2019, p. 165).
\end{abstract}

Crimes como esse, previstos no Título VI (Dos crimes contra a dignidade sexual) do código penal, antes do mencionado diploma, apenas podiam ser processados a partir de ação penal pública condicionada à representação, o que foi alterado para estabelecer que, a partir dali, sem exceções, a ação passaria a ser pública incondicionada, conforme a previsão do artigo 225 .

Conquanto, mais do que esse tipo de regulamentação, a implementação de políticas públicas que conscientizam a população e que protegem os direitos das mulheres, é de extrema importância. Será preciso compreender melhor essas "novas" dinâmicas sociais e os meios disponíveis para que se desenvolvam. Como leciona Ayres: "Em outras palavras, a criminalidade virtual é basicamente a mesma do crime terrestre com o qual estamos acostumados, diferenciando-se aquela somente em termos do meio" (2017, p. 222).

É por intermédio das máquinas (computadores, notebooks, tabletes, smartphones, entre outros) que pessoas munidas da falsa sensação de anonimato atacam outras pessoas. Com isso, há a necessidade de adaptações, inclusive de valores, para se ajustar à nova realidade em que vivemos. Muitas pessoas se utilizam da previsão constitucional de que é livre a manifestação do pensamento, mas se esquecem de que há responsabilidade para quem se excede, ou seja, a pessoa pode falar o que pensa, fazer o que lhe convém, todavia, isso não significa que não gere consequências. Invocar a liberdade de expressão para justificar determinadas atitudes cometidas por meio de um linchamento virtual, não inibe a caracterização de um crime, nem de reparação civil por danos. Implica dizer que, o direito à liberdade de expressão não permite que seja maculada a dignidade humana, logo, nenhum direito há de ser encarado como absoluto.

As mulheres são vítimas de uma violência simbólica, que interfere na psique delas, de forma que há um condicionamento da percepção de mundo que as mulheres têm. Assim, 
elas acabam tendo uma visão das regras de comportamento social, ditas adequadas, e delas próprias, exclusivamente pela perspectiva dos homens. Isso acaba limitando o exercício de liberdade da expressão das mulheres. Nas palavras de Ximenes, Mendes e Chia:

\footnotetext{
...elas sofrem de um tipo de violência que se esconde. A violência simbólica se institui por meio da adesão que o dominado não pode deixar de conceder ao dominador (e, portanto, à dominação), uma vez que ele não dispõe para pensá-la e para se pensar, ou melhor, para pensar sua relação com ele, mais que de instrumentos de conhecimento que ambos têm em comum e que, não sendo mais que a forma incorporada da relação de dominação, fazem esta relação ser vista como natural (2017, p. 2).
}

Constata-se, portanto, que o feminino é o sujeito de uma realidade própria, pois somente as mulheres sofrem e são discriminadas de maneira totalmente diferente se comparado com os homens. Pior ainda se, além de mulher, for negra, homossexual, índia, deficiente, pobre, enfim, se estiver no âmbito de uma violência interseccional. Essa violência e dominação se dão de tal forma que muitas mulheres, como já citado, não têm nem mesmo os meios necessários para reconhecer que estão inseridas em relações degeneradas de dominação e objetificação. Não se conscientizam disso.

Assim, vê-se que, a movimentação legislativa, ainda que no (discutível) âmbito penal, representa um avanço importante no enfrentamento aos linchamentos virtuais contra mulheres, no sentido de que veio para chamar a atenção para o fato e nos fazer discutir mais sobre essa condição de marginalização histórica que persiste, ainda mais se for levado em conta que a lei se volta para a raiz do linchamento virtual, que é a própria divulgação das imagens íntimas, e não apenas aos ataques de ódio. Contudo, é necessário que se vá muito além disso, é preciso que se deflagre uma mudança de cultura, de paradigma, por meio da conscientização dos limites da liberdade de cada indivíduo, haja vista as consequências devastadoras que esse tipo de comportamento nocivo pode ter sobre as vítimas.

Ainda há, infelizmente, uma crença masculina de que o corpo feminino é uma espécie prazerosa de objeto que está à disposição de seus desejos. E, é assim, que práticas como a pornografia de vingança acontecem cada vez mais, com as mulheres sofrendo os prejuízos de toda ordem, em especial aqueles de cunho psicológico, que comprometem a própria visão de si, como também o julgamento alheio, o seu ambiente familiar e profissional.

\section{Por Que aS MUlheres SÃo aS Vítimas PREFERENCIAIS DESSE TIPO DE CONDUTA? UMA PERSPECTIVA DA CRIMINOLOGIA FEMINISTA}

Para que possamos compreender melhor a lógica do presente capítulo, é preciso que deixemos claro desde o início que as inúmeras formas de violência contra as mulheres possuem origem histórica, e, embora nossa abordagem não seja propriamente histórica, será preciso uma contextualização inicial. Logo, os problemas historicamente enfrentados pelas mulheres são fruto de uma construção social, não de uma circunstância isolada, cuja responsabilidade pertence a todos e todas. Os preconceitos, as discriminações, bem como, os 
mais diversos tipos de desigualdades construídas, devem-se, portanto, ao modelo patriarcal de sociedade. Segundo Bárbara Madruga da Cunha, "ao se falar em 'violência contra a mulher' pretende-se, na realidade, remeter às relações patriarcais de gênero e a desproporcionalidade que elas estabelecem na relação de convívio, identidade e sexualidade entre os sexos" (2014, p. 150).

As sociedades patriarcais têm como característica principal o tipo de educação que os homens recebem, sendo esses criados para que, desde muito pequenos, aprendam a comandar a família, pelo simples fato de serem homens, sendo assim estimulados a atingir seus objetivos de vida. Conforme Bárbara Madruga da Cunha, "o patriarcado é, por conseguinte, uma especificidade das relações de gênero, estabelecendo, a partir delas, um processo de dominação-subordinação" (2014, p. 154). A sociedade é moldada para privilegiar os papéis assumidos pelos homens, tomando por base os padrões do comportamento masculino. Não foi por acaso, portanto, que Deivy Ferreira Carneiro (2015, p. 345), ao pesquisar 294 processos criminais de calúnia e injúria, que abordavam a reputação feminina, entre os anos de 1854 e 1941, em Juiz de Fora/MG, chegou à conclusão de que, na maior parte dos casos, as ofensas eram direcionadas contra a quebra de normas sociais protagonizadas por mulheres.

Nesse processo de estruturação, no caso das mulheres, essas, desde pequenas, são vistas e representadas de forma inferiorizada, sendo estimuladas a cuidarem apenas da casa, da família e dos filhos, ou seja, devem sempre obedecer e serem submissas aos outros (homens). E assim são sistematicamente ensinadas, em situações em que se observam, inclusive, que até os presentes comumente dados às meninas são relacionados às atividades domésticas, como vassouras, fogões, panelas, entre outros. Para Bárbara Madruga da Cunha, a ideia de gênero é "uma categoria criada para demonstrar que a grande maioria das diferenças entre os sexos são construídas social e culturalmente a partir de papéis sociais diferenciados que, na ordem patriarcal, criam polos de dominação e submissão" (2014, p. 150).

Nesse passo, a violência contra as mulheres se caracteriza como sendo instrumento essencial à manutenção das desigualdades construídas historicamente. A violência de gênero, portanto, é uma forma de dominação do homem sobre a mulher que deveria ter "aprendido" a ser submissa, isto é, uma relação de poder desigual, que foi historicamente construída e que tolhe a liberdade das mulheres, de modo a mantê-la na condição de submissa. Como aduz Vera Regina de Andrade, "como a esfera da reprodução natural, e aparecendo como o lugar das relações familiares (casamento, sexualidade reprodutora, filiação e trabalho doméstico) tem seu protagonismo reservado à mulher, por meio do aprisionamento de sua sexualidade na função reprodutora e de seu trabalho no cuidado do lar e dos filhos" (2005, p. 85).

Da perspectiva de Mariana Nóbrega de Lucena, o patriarcado "se manifestaria no controle dos corpos femininos, notadamente pelo controle da maternidade e da sexualidade das mulheres" (2018, p. 3). Fica evidente que a própria sociedade ao longo dos tempos vem impondo regras de recato e pudor, estabelecendo como deve ser o comportamento das mulheres na sociedade; e, como já foi dito, aquelas que agem de forma contrária, rebelam-se de algum modo, são geralmente agredidas e sofrem diversos tipos de violência, por exemplo, nos casos dos linchamentos virtuais a partir das redes sociais, o que não coaduna com um regime que se pretende como democrático. Assim, como explicita Amanda Bessoni, "essa dificuldade de superação da história de sujeição feminina 
reflete-se emblematicamente na violência sexual, na violência de gênero e na construção do Direito Penal" (2018, p. 43).

Porém, como a tendência é a de que, com o passar do tempo, as coisas "evoluam", ${ }^{4}$ ou se adaptem, a maneira pela qual as mulheres sofrem esses tipos de violência também "evoluiu", causando uma espécie de continuidade dessa repressão de cunho moralizante. O que antes ficava restrito ao mero boca a boca, comprometendo a mulher em seu espaço de convivência mais próximo, agora tem potencial de dano muito maior, por causa da repercussão evidenciada nas redes sociais. Nos dias atuais, as mulheres sofrem esse tipo de violência por meio da internet, isto é, a tentativa de submissão da mulher diante do homem continua, embora com características diferentes. Como explica Mariana Barrêto Nóbrega de Lucena:

Para utilização dessas práticas de justiçamento, os novos movimentos sociais utilizam dos mesmos argumentos utilizados tradicionalmente para justificar linchamentos convencionais: a justificativa de que o Estado e suas instituições não resolvem a contento ou ignoram as demandas dos movimentos sociais (2018, p. 8).

Diante do exposto, é mais do que necessário o reconhecimento da violência contra a mulher como sendo uma legítima violação dos direitos humanos, daí a ideia de lesa-dignidade já exposta, haja vista que as mulheres historicamente tenham sofrido com o abuso, o assédio, a tentativa de controle, principalmente de seus corpos, por parte dos homens e da sociedade patriarcal em geral, e, com isso, têm recebido uma resposta um tanto quanto ineficaz do próprio Estado brasileiro, razão pela qual, como assevera Mariana Barrêto Nóbrega de Lucena, "é importante estimular denúncias de violências sofridas pelas redes sociais, tanto porque seria terapêutico para as vítimas como porque seria importante expor o agressor para evitar que este vitimasse novas pessoas" (2018, p. 11).

Portanto, parece-nos essencial estimular uma via educacional acerca do assunto, especialmente para uma melhor solução e enfrentamento desse tipo de problema. Somente assim há de se permitir uma imprescindível mudança cultural. Com relação à perpetuação dessas práticas sofridas pelas mulheres, nos esclarecem Valente, Neris, Ruiz e Bulgarelli, que:

\footnotetext{
Para as ciências sociais, e em especial para a antropologia, violência e sexualidade tendem a ser compreendidos antes como categorias relacionais do que como conceitos pré-estabelecidos. Isso quer dizer que se tratam de relações construídas na cultura, e não necessariamente universalmente válidas (2016, p. 11).
}

Logo, temos práticas enraizadas na nossa cultura, que ainda são vistas, por muitos, como algo legítimo, às vezes até pelas próprias mulheres, que aceitam o papel ao qual são relegadas socialmente, correspondendo às expectativas sobre elas. Entretanto, é necessário

4 É importante ter em mente que evoluir significa passar por um processo gradual de transformação e nem sempre essa transformação se dá de forma positiva, pode ocorrer tanto de modo que mantém o status quo, quanto de forma negativa. Aqui a expressão utilizada é no seu sentido negativo. Para que se possa aprofundar sobre a análise crítica do termo: BOLLSANELLO, Maria Augusta. Darwinismo social, eugenia e racismo "científico": sua repercussão na sociedade e na educação brasileiras. Educar, n. 12. Curitiba: Editora da UFPR, 1996, p. 153-165. Disponível em: http://www.scielo.br/pdf/er/n12/n12a14.pdf. 
descontruir essa "naturalização" da violência e objetificação das mulheres com relação ao seu corpo. Na análise de Valente, Neris, Ruiz e Bulgarelli, o acompanhamento de casos por eles realizado:

[...] mostra claramente que, com poucas exceções, é o sexo feminino que é afetado, ainda que a exposição seja de um casal heterossexual. Apresenta-se diante de nós o suposto paradoxo de que, em tempos de superexposição e desvalorização da privacidade, e possivelmente de uma certa liberalização dos costumes, principalmente por adolescentes, a exibição da nudez e de cenas sexuais envolvendo mulheres ainda seja um tabu tão extremo, com o condão até mesmo de destruir vidas (2016, p. 13).

Sempre houve, da nossa forma de ver as coisas, uma espécie de crença masculina de que o corpo das mulheres deve estar à disposição de seus desejos e caprichos, como se reles objeto fosse, o que nos parece persistir, embora agora com mais resistência. A propósito, de quem é o corpo que serve como principal inspiração para a filosofia dos famosos contos do Marquês de Sade? Da mulher, é claro. Nele é comum ver a mulher ser representada como objeto de apreciação, experimentação ou serviço (SADE, 2008). É, portanto, diante desse quadro que aqui se defende que as mulheres são sujeitas de uma realidade própria, em especial na sociedade brasileira, pois vistas como uma coisa e não como sujeitos de direitos, como, aliás, qualquer ser humano deveria ser tratado. É nesse sentido a análise de Valente, Neris, Ruiz e Bulgarelli:

\begin{abstract}
Na esfera da sexualidade, regime de visibilidade é uma noção que busca sintetizar a maneira como uma sociedade confere reconhecimento e torna visíveis certos arranjos amorosos, enquanto controla outras maneiras de se relacionar por meio de vigilância moral, da coibição de sua expressão pública, em suma, pela manutenção dessas outras formas amorosas e sexuais em relativa discrição ou invisibilidade (2016, p. 16,17).
\end{abstract}

Nesse contexto, as mulheres sofrem de violências muito próprias, que interferem na maneira como acabam se enxergando e sendo enxergadas pela sociedade, pois há a disseminação de uma "má fama". Com isso, algumas vítimas acabam se isolando do convívio social e, nos piores casos, chegam até a cometer suicídio, como já foi mencionado. Fazendo-se assim, mais uma vez, a necessidade de um olhar mais atento inclusive do ordenamento jurídico, vez que, conforme ensinam Ximenes, Mendes e Chia:

\footnotetext{
Um traço persistente que se verifica nos manuais analisados é uma pretensão de legitimação ou de atenuação da gravidade da conduta do agente com base em qualidades pessoais "negativas" da vítima mulher. Aqui expressões como "má fama", "desonestidade" e "conduta regrada" demonstram na prática social que a doutrina representa uma reprodução da estrutura hierarquizada e de dominação que se perpetua no campo jurídico (2017, p. 8).
}

Além do mais, não raramente as mulheres são indagadas das razões por terem enviado ou permitido, quando isso é possível, certo tipo de foto ou filmagem em momento íntimo. 
Mas isso não há de ser relevante quando o conteúdo é utilizado, sem o seu consentimento, para maculá-la e ofender a sua dignidade. Segundo explicam Junior e Meirelles:

\begin{abstract}
...os esforços de combate à pornografia de vingança parecem seguir o mesmo errôneo caminho ao redor do mundo: a prevenção, ou seja, orienta-se que a mulher não tire e/ou envie a alguém suas fotos íntimas. Essa medida, de certo modo, atribui à mulher uma parcela de culpa pelo ato, tratando-a como algo totalmente evitável pela vítima $(2015$, p. 91$)$.
\end{abstract}

Ressalte-se, portanto, que os comportamentos das mulheres, mesmo os de cunho sexual, cabem única e exclusivamente a elas, e devem ser respeitados, desde que, como é evidente, não ofendam bem protegido pela normatização legal. Como elas devem agir e como elas devem ou não se comportar depende delas, sem que para isso precisem passar por qualquer tipo de autorização. Veja-se que, conforme Bárbara Madruga da Cunha, "a partir da ideologia sexista, o homem, tal como foi construído, é que sabe o que é melhor para a mulher, a família e a sociedade" (2014, p. 151).

Diante de tais circunstâncias, é imprescindível a manutenção da luta por igualdade de tratamento social e estatal. Longe de se constituir na busca por privilégios, como muitos, sobretudo homens, encaram. Ver respeitados direitos e garantias fundamentais é o mínimo que se espera de um ambiente que se pretende como democrático. Somente assim essas práticas nocivas podem ser enfrentadas. No entanto, da perspectiva de Bárbara Madruga da Cunha:

\begin{abstract}
A luta por direitos não pode, portanto, ser encarada como o fim último para a mudança social, mas como mecanismo de articulação das minorias políticas e de construção de identidade coletiva e de certo grau de empoderamento destes grupos (2014, p. 158).
\end{abstract}

As mulheres que convivem com essa realidade precisam, em primeiro lugar, entender que isso não é algo que possa ser naturalizado, haja vista que são padrões que muitas vezes levam a uma autoculpabilização. É dessa maneira que Bárbara Madruga da Cunha explica que:

\footnotetext{
Uma mulher que sofre violências sistemáticas, que se encontra sob o total controle do marido, que naturaliza as opressões diárias que vive, que reprime sua sexualidade, encontrará muito mais dificuldades para se enxergar como sujeito ativo capaz de modificar a realidade social, de lutar para sua libertação e empoderamento (2014, p. 158).
}

Ademais, a internet, como meio de disponibilidade para um número tão grande de pessoas, permite-nos ainda que essa mesma violência contra as mulheres seja objeto de uma visibilidade que antes não existia, que o debate com um alcance maior, ou seja, permite que haja mais denúncias e conhecimento do que se passa na vida das mulheres, de como é difícil ser mulher e sofrer com violências que só quem é mulher sabe e sofre. Ou seja, o mesmo meio que serve para ferir, também pode ser utilizado para curar.

Por fim, a expectativa é a de que, sobretudo pela via educacional, sejam implementadas políticas públicas para a conscientização social com o fim de humanizar a figura 
das mulheres, para que elas não sejam vistas tão-somente como corpos que servem para satisfação do sexo masculino, para que seja reduzida a motivação de padrões de comportamento que propiciam a perpetuação desse tipo de violência. Assim, a sociedade que tratar as mulheres como sujeitas de direitos e deveres, e acima de tudo como seres humanos, cujo valor não é medido por parâmetros relacionados ao seu comportamento sexual, certamente não permitiria com tanta facilidade linchamentos virtuais tendo como pretexto seus comportamentos sexuais.

\section{CONSIDERAÇões FINAIS}

O objetivo principal da investigação aqui realizada foi o de analisar criticamente as implicações penais do linchamento virtual no tocante ao comportamento sexual das mulheres, além de avaliar como a literatura tem se comportado diante desses casos. São as mulheres as vítimas preferenciais dos linchamentos virtuais, sendo que nossa análise foi no sentido de refletir sobre como o direito penal tem agido perante tais situações. Com o advento da internet e, por conseguinte, das redes sociais, tem se permitido perpetuar violências contra as mulheres.

Nesse sentido, os linchamentos, que anteriormente se realizavam na esfera física, migraram para o ambiente virtual, com os chamados linchamentos virtuais, que, assim como o físico, têm também a pretensão de correção moral contra aqueles que fogem de condutas preestabelecidas. É uma prática ritualizada em conjunto, muitas vezes movida pelo ódio e pelo sentimento de vingança. É inegável que a internet tem impacto direto na realidade humana, ou seja, é uma ampliação da mesma, com maior propagação daquilo que se realiza nela, provocando graves consequências, com proporções inimagináveis na vida de quem é linchado.

A captura e a divulgação de imagens de cunho íntimo, sem consentimento, com a intenção de prejudicar a vida e a imagem das pessoas, como vimos, para além das previsões já existentes, passaram a ser tipificadas a partir das leis 13.718/2018 e 13.772/2018, com as previsões dos artigos 216-B e 218-C no código penal. Entretanto, isso não é o suficiente para que essa prática não exista mais. Conquistar direitos para as mulheres é importante, no entanto, é necessária uma via educacional para uma melhor compreensão e conscientização a respeito desse tipo de violência historicamente arraigada. Mais do que violências simbólicas, as mulheres que são linchadas virtualmente sofrem de um tipo de violência muito particular, com consequências tanto emocionais, quanto profissionais e na própria visão de si.

Constatou-se, portanto, o quanto esse tipo de violência está enraizado na cultura brasileira, que naturaliza desigualdades em todos os aspectos: econômica, social, sexual etc. Há um verdadeiro sistema de controle moral sobre os corpos femininos, como se estes existissem para a mera satisfação do gênero oposto e que com isso as mulheres devessem seguir as regras estabelecidas como certas para um comportamento de uma mulher considerada como honrada. Aquelas que fogem dessa padronização chegam mesmo a ter suas imagens íntimas divulgadas, no sentido de sofrerem um julgamento moral da sociedade e de terem suas vidas devastadas.

Dessa maneira, concluímos atendidos os objetivos propostos e articuladas coerentemente as hipóteses sustentadas ao longo da presente investigação, tudo na medida em que 
constatamos que as mulheres ainda são as que mais sofrem críticas com relação ao seu comportamento sexual, sendo a exposição de seu corpo vista, na generalidade, de maneira negativa inclusive também no ambiente virtual, continuando assim a realidade de uma sociedade que ainda vive de modo patriarcal, onde o homem tem a dominação/controle sobre a vida da mulher.

\section{REFERÊNCIAS}

ANDRADE, Vera Regina Pereira de. A Soberania Patriarcal: O Sistema de Justiça Criminal no Tratamento da Violência Sexual Contra a Mulher. Revista Sequência, nº. 50, p. 71-102, jul. 2005. Disponível em: https://periodicos.ufsc.br/index.php/sequencia/article/ view/15185. Acesso em: $1^{\circ}$. out. 2019.

BESSONI, Amanda. Abuso sexual nos transportes públicos: problematização do direito penal sexual sob a perspectiva de gênero. GOMES, Mariângela Gama de Magalhães; FALAVIGNO, Chiavelli Facenda; MATA, Jéssica da. (Org.). Questões de gênero: uma abordagem sob a ótica das ciências criminais. Belo Horizonte: Editora D’Plácido, 2018, p. $37-62$.

BITENCOURT, Cezar Roberto. Tratado de direito penal: parte especial 2: crimes contra a pessoa, 19. ed. São Paulo: Saraiva Educação, 2019.

BITENCOURT, Cezar Roberto. Tratado de direito penal: parte especial 4: crimes contra a dignidade sexual até crimes contra a fé pública, 13. ed. São Paulo: Saraiva Educação, 2019.

BOLLSANELLO, Maria Augusta. Darwinismo social, eugenia e racismo "científico": sua repercussão na sociedade e na educação brasileiras. Educar, n. 12. Curitiba: Editora da UFPR, 1996. p. 153-165. Disponível em: http://www.scielo.br/pdf/er/n12/n12a14.pdf. Acesso em: 9 out. 2019.

BRASIL. Constituição Federal (1988). Constituição da República Federativa do Brasil. Diário Oficial da República Federativa do Brasil, Brasília, DF, 5 de outubro de 1988. Disponível em: http://www.planalto.gov.br/ccivil_03/constituicao/constituicaocompilado. htm. Acesso em: 30 set. 2019.

BRASIL. Decreto-Lei n⿳. 2.448, de 7 de dezembro de 1940. Código Penal. Brasília, DF: Presidência da República, 7 dez. 1940. Disponível em: http://www.planalto.gov.br/ccivil_03/leis/19099.htm. Acesso em: 1º. out. 2019.

BRASIL. Lei $\mathbf{n}^{\mathbf{0}}$. 13.772, de 19 de dezembro de 2018. Altera a Lei $\mathrm{n}^{\mathbf{0}} 11.340$, de 7 de agosto de 2006 (Lei Maria da Penha), e o Decreto-Lei n ${ }^{\circ}$ 2.848, de 7 de dezembro de 1940 (Código Penal), para reconhecer que a violação da intimidade da mulher configura violência doméstica e familiar e para criminalizar o registro não autorizado de conteúdo com cena de 
nudez ou ato sexual ou libidinoso de caráter íntimo e privado. Brasília, DF: Presidência da República, 25 set. 2018. Disponível em: http://www.planalto.gov.br/ccivil_03/_Ato20152018/2018/Lei/L13718.htm. Acesso em: 22 set. 2019.

BRASIL. Lei $\mathbf{n}^{\mathbf{0}}$. 13.718, de 24 de setembro de 2018. Altera o Decreto-Lei $\mathrm{n}^{\circ} .2 .848$, de 7 de dezembro de 1940 (Código Penal), para tipificar os crimes de importunação sexual e de divulgação de cena de estupro [...]; e revoga dispositivo do Decreto-Lei ${ }^{\circ}$. 3.688, de 3 de outubro de 1941 (Lei das Contravenções Penais). Brasília, DF: Presidência da República, 25 set. 2018. Disponível em: http://www.planalto.gov.br/ccivil_03/_Ato2015-2018/2018/ Lei/L13718.htm. Acesso em: 22 set. 2019.

BRASIL. Lei $\mathbf{n}^{\mathbf{0}} \mathbf{9 . 0 9 9}$, de 26 de setembro de 1995. Dispõe sobre os Juizados Especiais Cíveis e Criminais e dá outras providências. Brasília, DF: Presidência da República, 27 set. 1995. Disponível em: http://www.planalto.gov.br/ccivil_03/leis/19099.htm. Acesso em: 1º. out. 2019.

CARNEIRO, Deivy Ferreira. Mulheres, insultos, fofocas e reputação sexual. Uma breve análise das relações de gênero através de processos criminais de calúnia e injúria (Juiz de Fora, 1854-1941). Revista Brasileira de Ciências Criminais, São Paulo, v. 20, n. 94, p. 345-361., jan./fev. 2012. Disponível em: http://201.23.85.222/biblioteca/index.asp?codigo_sophia=91383. Acesso em: 19 out. 2019.

CASTELLS, Manuel. A Galáxia da Internet: Reflexões sobre a internet, os negócios e a sociedade. Rio de Janeiro: Zahar, 2003.

CASTELLS, Manuel. A sociedade em rede. Tradução Roneide Venancio Majer Tradução, 17. ed., rev. e ampl. São Paulo: Paz e Terra, 2016 (A era da informação: economia, sociedade e cultura; v. 1).

CUNHA, Bárbara Madruga da. Violência contra a mulher, direito e patriarcado: perspectivas de combate à violência de gênero. Universidade Federal do Paraná, 2014 (Artigo classificado em $7^{\circ}$. lugar na XVI Jornada de Iniciação Científica de Direito da UFPR 2014). Disponível em: http://www.direito.ufpr.br. Acesso em: 4 jun. 2019.

FERREIRA, Aurélio Buarque de Holanda. Miniaurélio Século XXI: O minidicionário da língua portuguesa. ANJOS, Margarida dos; FERREIRA, Marina Baird (coord. edição). ANJOS, Margarida dos, et al. (lexicografia, 5. ed. rev. ampl. Rio de Janeiro: Nova Fronteira: 2001.

FRANÇA, Leandro Ayres. Cibercriminologias. In: CARLEN, Pat; FRANÇA, Leandro Ayres (Org.). Criminologias alternativas. Porto Alegre: Canal Ciências Criminais, 2017, p. 221-243.

LÉVY, Pierre. Cibercultura. Tradução Carlos Irineu da Costa, 1. ed. São Paulo: Editora 34, 1999. 
LÉVY, Pierre. O que é virtual? Tradução Paulo Neves. São Paulo: Editora 34, 1996, 157p.

LUCENA, Mariana Barrêto Nóbrega de. Ativismo Feminista e Punitivismo: Problematizando os linchamentos virtuais. Revista Brasileira de Ciências Criminais, v. 146/2018, ago. 2018, p. 457-481. DTR $2018 \backslash 18288$.

MACEDO, Karen Tank Mercuri. Linchamentos Virtuais: Paradoxos nas relações sociais contemporâneas. Limeira, SP: 2016. Apresentada originalmente como dissertação de mestrado, Universidade Estadual de Campinas, 2016. Disponível em: http://repositorio.unicamp.br/bitstream/REPOSIP/321038/1/Mercuri_KarenTank_M.pdf. Acesso em: 22/07/2019.

MARTINS, José de Souza. Linchamentos: a justiça popular no Brasil. São Paulo: Contexto, 2015.

MARTINS, José de Souza. Linchamentos: a justiça popular no Brasil. [Entrevista publicada por Mauro Donato. Diário do Centro do Mundo, 15 mar. 2015. Disponível em: https:// www.diariodocentrodomundo.com.br/entrevista-o-papel-do-linchamento-virtual-no-brasil-segundo-o-cientista-social-jose-martins/. Acesso em: 20 jul. 2019.

MORELLI JUNIOR, Amirton Archanjo; MEIRELLES, Flávia Sanna Leal de. Violência de Gênero no Século XXI: A pornografia de vingança. Revista da EMERJ, Rio de Janeiro, v. 18, n. 71, nov. dez. 2015, p. 88-93. Disponível em: http://www.emerj.tjrj.jus.br/revistaemerj_online/edicoes/revista71/revista71_sumario.htm. Acesso em: 9 out. 2019.

SADE, Marquês de. A filosofia na alcova. Trad. Contador Borges. São Paulo: Iluminuras, 2008.

SILVA, Phillipe Giovanni Rocha Martins da. Pornografia não consentida e linchamento virtual: uma análise da (re)territorialização da violência contra a mulher no ciberespaço. João Pessoa, PB: 2018. Dissertação apresentada ao Programa de Pós-Graduação em Direitos Humanos, Cidadania e Políticas Públicas da Universidade Federal da Paraíba (PPGDH/ UFPB). Disponível em: https://repositorio.ufpb.br/jspui/handle/123456789/14626. Acesso em: 14 set. 2019.

VALENTE, Mariana Giorgetti; NERIS, Natália; RUIZ, Juliana Pacetta; BULGARELLI, Lucas. O Corpo é o Código: estratégias jurídicas de enfrentamento ao revenge porn no Brasil. São Paulo: InternetLab, 2016. Disponível em: http://www.internetlab.org.br/wpcontent/uploads/2016/07/OCorpoOCodigo.pdf. Acesso em: 1º out. 2019.

XIMENES, Julia Maurmann; MENDES, Soraia da Rosa; CHIA, Rodrigo. E quando a vítima é a mulher? Uma análise crítica do discurso das principais obras de direito penal e a violência simbólica no tratamento das mulheres vítimas de crimes contra a dignidade sexual. Revista Brasileira de Ciências Criminais, v. 130/2017, abr. 2017, p. 349-367. DTR $\ 2017 \backslash 674$. 
IMPLICAÇÕES PENAIS DO LINCHAMENTO VIRTUAL COM FOCO NO COMPORTAMENTO SEXUAL DA MULHER: DISSEMINAÇÃO DO DISCURSO DE ÓDIO NAS RELAÇÕES DE GÊNERO SOB UMA PERSPECTIVA CRIMINOLÓGICA FEMINISTA

\section{DADOS DOS AUTORES}

\section{Francisco França Júnior}

Doutorando e mestre pela Universidade de Coimbra (Portugal); Professor no Centro Universitário CESMAC (Maceió/AL). fafjunior2016@gmail.com

\section{Ana Cecília de Morais e Silva Dantas}

Doutora pela PUC/RS; Mestra pela Universidade Federal de Alagoas - UFAL; Professora e coordenadora do grupo de Gênero e Direito no Centro Universitário CESMAC (Maceió/ AL).acmsdantas@gmail.com.br

\section{Roneide Lucia da Silva}

Graduanda em Direito no Centro Universitário CESMAC (Maceió/AL). oneidel19@gmail. com.br.

Submetido em: 12-11-2019

Aceito em: 9-10-2020 